\title{
"Chinese English" and Its Implication on C-E Translation of Chinese Specific Expressions
}

\author{
Yi Chen \\ Beijing University of Posts and Telecommunications, Beijing, China \\ Email: norachenyi@yahoo.com
}

\begin{abstract}
This paper attempts to clarify Chinese English and explore its origin, focusing on the important role of Chinese English resulted in the translation of expressions of Chinese specific expressions. In view of the important role of Chinese English in cross-cultural communication, the paper proposes that the translators should take a justified attitude to "Chinese English" rather than avoid it as unnecessary or bad English and the expressions with Chinese peculiarity should be particularly heeded to in $\mathrm{C}$-E translation. It also raises a few translation strategies in C-E interpretation of the Chinese specific expressions for a better communicative effect in cross-cultural communication.
\end{abstract}

Index Terms - Chinese English, C-E translation, cross-cultural communication, interpreting approaches

\section{INTRODUCTION}

With China opening itself more to the outside world and the increasing translation activities, "Chinese English" emerges as a popular term for English learners in China nowadays and can be found in many oral and written texts. This term was first proposed by Chuangui Ge, a Chinese scholar who argues that "the expressions with Chinese characteristics do not belong to the English expressions habitually spoken in English speaking countries" (Ge 1984). He therefore argues that it should be called "Chinese English". Since then, a few scholars also talked about "Chinese English". (Huang 1998, Jia, Xiang 1997, Li 2008) and most believe that "Chinese English" is an undeniable existence, or rather "a variation of English" (Wang 1991).

Because of the inevitable differences in historical tradition, cultural preference, and the way of thinking between China and the Western world, it is often hard for Chinese specific expressions to find "the closest natural equivalence" (Nida \& Taber 1969:12) in English. As a result, The English translations of such expressions are likely to become "Chinese English". Through years of development in the midst of cross-national communication in terms of both language and culture, some of the "Chinese English" has become a conspicuous part of English like other loan words. However, "Chinese English" is characteristic of China since it involves a lot of expressions in politics, economy, culture, history and social situation in specific Chinese context. Therefore, while "Chinese English" looks like standard English both in meaning and in grammar, it still sounds a bit foreign to native speakers of English. It might be safe to say that "Chinese English" is a combination of Chinese culture and language and English language.

As China pushes forward its globalization, it is inevitable that "Chinese English" will arise as a greater concern in cross-cultural contact as more expressions with Chinese characteristics with the coverage of every aspect are to be introduced into English. A close study of "Chinese English" might help to understand it better.

\section{THE ORIGIN OF THE CHINESE ENGLISH}

\section{A. Established Way of Speaking}

Among the many factors contributing to the formation of "Chinese English", the most common one is the established way of speaking after years of practice by numerous people. When an expression is used and frequently imitated by others, it is likely to become popular and will gradually be accepted by the general public as standard expressions. Usually, these expressions are vivid and expressive, appealing to public interest in certain period of time. For instance, Chinese use “摆谱儿”(bai pu er, literally “put a musical score”) to mean "to put on airs", “to show off” or “to keep up appearances". It is so used because musical score is somewhat elegant and the person who puts it appears to have a tint of being proud and have a high opinion of himself. “没谱”(mei pu, literally “no score”) is another expression with “谱”(pu), meaning having no idea or being uncertain. When somebody says “这没谱”(zhe mei pu, literally “This does not have score ”), he actually means that it's hard to know if this will happen. Chinese expression “吃闭门美” (chi bi men geng, literally eating close-door dinner) to mean "be given cold-shoulder”. They use “扣帽子” (kou mao zi, literally "place a hat over") with a implication of defining it by covering it with a hat to mean "put a label on". These expressions, slight disapproval or joking in tone, are quite vivid Chinese developed through time and established in everyday Chinese.

\section{B. The Influences of Cultural Tradition}


As every language is influenced by the cultural tradition of that country, Chinese is no exception. A lot of Chinese-specific expressions have to do with the Chinese tradition and custom. The Spring Festival (Chinese Lunar New Year) is the most important festival in China, therefore, a number of expressions are related to it. “拜年”(bai nian, literally "kneeing or bowing to pay a New Year call"), for example, usually takes place during the Spring Festival when people pay New Year call to each other. This expression especially embodies a particular Chinese tradition of bowing to or kneeling to wish one's elders or superiors a happy new year. Another expression “压岁钱” (ya sui qian, literally “age pressing money") is the money the elders give to children as a New Year gift. It has to do with the origin of the Spring Festival. Legend has it that a demon called “崇” (sui) used to come out at night to frighten the kids in the village. People wrapped some money into a red paper and give it to the kids as “压崇钱” (ya sui qian), thus keeping “崇” off them. “崇” has the same pronunciation as “岁” in Chinese, so this expression later became “压岁钱”(ya sui qian) ${ }^{1}$.

Words and expressions resulted from Chinese tradition and custom can be amazingly large in number. Since China is a country with a long history and old tradition, expressions related to its culture are considerable in number. Besides the above mentioned holiday related expressions, the naming of places, dishes and people can also find their profound influence by the cultural characteristics of the Chinese nation. Unlike English, most Chinese names bear the meaning reflecting the psychological or the ethical characteristics of the people. Yucheng Song of the Song Dynasty said that "People today often name their kids with 'wen'(literature), 'wu'(marshal arts), 'fu' (wealth) and 'gui'(honorable)" (Zhao 1988:111) which fully represent parents' wish of their children to live a desired life. Moreover, because Chinese people attach great importance to moral standard, a lot of names have "de"(virtue) in it. "Mengde Cao", "Xuande Liu" and "De Zhu" are just a few examples. These cultural bound words and expressions, when translated into English, are likely to result in "Chinese English".

\section{The Emergence of New Expressions}

In recent years, new expressions are emerging at an accelerated speed, attributed mainly to people's new ways of life and the current Chinese situation. These expressions cover nearly every field, from politics to environment, from sports to society, most being the reflection of social changes. For example, ever since China's reform on housing policy ${ }^{3}$, there appeared a lot of expressions on the new housing policy. People use “福利分房”(fu li fen fang) to mean welfare-oriented public housing distribution system, making a distinction from “商品房” (shang pin fang, meaning commercial housing). The new policy also encourages the tapping of more land and old houses for new buildings. When the real estate companies buy out the old houses and give the house owners money or a new houses somewhere else as a compensation, the expression “搬迁户”(ban qian hu, meaning relocated families) thus appears. For those families who cannot afford commercial houses, the government carries out the Housing Project for low-income families called “安居工程”(an ju gong cheng). A most recent new word might be “房奴”(fang nu, literally house slaves) which is a vivid reflection of today's Chinese who has bought a house and have to work very hard to pay up the mortgage.

The newly emerged expressions are not limited to a specific area since each field has some new phenomena fostering new words and expressions into existence. Therefore, the above-mentioned house-related words are only a corner of the iceberg. Words and expressions embodying new phenomena in other fields are by no means rare. For example, increasing economic activities in China in the past years have led to the emergence of some legal problems. A most commonly practiced illegal activity by companies might be to avoid paying taxes, thus the expression “偷税漏税”(tou shui lou shui, meaning tax evasion). “打假”(da jia), an expression meaning fighting against the counterfeit, is a result of the rampant activities in making and selling counterfeit goods . “扫黄打非”(sao huang da fei) is also a new legal term meaning eliminating pornography and illegal publications. All these examples serve to testify the prevalence of new expressions.

\section{THE IMPLICATION OF THE "CHINESE ENGLISH" IN CHINESE-ENGLISH INTERPRETATION}

With China opening itself more to the outside world and the impending globalization, the role of cross-cultural communication is increasingly important. Cross-cultural communication is largely dependent upon language translation, especially its oral form of interpretation which always proves to be the best way to reach understanding between different cultures with its directness and timeliness. In this case, Chinese English is not only inevitable, but also essential, naturally posing an important aspect of cross cultural communication.

\section{A. The Importance of "Chinese English” in Cross-cultural Communication}

\footnotetext{
${ }^{1}$ It is said that a demon called “崇” used to go out during the night and frightens the kids. The adults give each kid a red envelop with money in it to keep the demon away. People called the money “崇” which has the same pronunciation as “岁” (sui). With time going on, this was later called "'”(yasuisqian). Chinese custom has it that ya sui qian can help kids have a peaceful and healthy life. (sources: Chinese Folk Overview:53)

2 Mengde Cao (155-202) and Xuande Liu (161-223) are the two emperors of the Three Kingdom period. De Zhu (1886-1976) is one of the founders of the People's Republic of China.

${ }^{3}$ In early 1980 s, China carried out the housing reform, eliminating all the state allocated houses and encouraging residents to buy the house with their own expense. The commercialization of housing was practiced nation wide from 1994. This was called commercial houses as is different from previous welfare houses. (sources: china.com.cn)
} 
Different nations have different behavior patterns and different cultural practices, with the most important form of representation being the languages. English and Chinese, as two distinctive languages, belong to and reflect the cultural practices of two different nations. With the ever-increasing social, cultural and political communications between Chinese and the English speaking countries, English culture, like the holiday traditions, has been assimilated into Chinese culture gradually. Nowadays, people in China have begun to celebrate Christmas and other important festivals of English speaking countries. A lot of words borrowed from English have become a part of China's everyday vocabulary, sha long (salon), ke le (cola), to mention just a few. There is no denial that the English tradition has aggressively left its print on the Chinese language resulted from the English learning boom in the past few years.

Cross cultural communication involves two way exchanges of cultures and languages. It is the communication between the local culture (source culture) and the target culture. Since "the loss of local culture means the loss of one side of communication" ( $\mathrm{Li}, 2006$ ), local culture is always at one end of communication and is indispensible for its completion. Therefore, while China is enthusiastically understanding and accepting English culture facilitated by English language and its Chinese translation, it is also eager to introduce itself, including its social, political and cultural characteristics, to English speaking countries. The cross-cultural communication depends on language translation or interpretation, almost the only ways to reach understanding between different languages.

When Chinese is translated into English, a large number of daily expressions with particular Chinese characteristics are hard to be properly put into established English. Not only native English-speaking people find them awkward, Chinese who major in English language also find it unnatural because they don't sound like English. These expressions often become "Chinese English".

"Chinese English", with particular Chinese flavor and accepted meaning in English, might sound a bit alien to the native English speakers at the beginning. But with the deepening of communication and understanding between the two languages, these expressions are likely to be accepted by more people and gradually become part of the English language. When the English-speaking people get to know what it is like in China's social context, they might find it much easier to accept it since it pretty well represents the special social context in China. As a result, "Chinese English" will gradually gain acceptance and is likely to develop into everyday English. Actually, this has already happened. "Chinese English" like jiaozi (meaning Chinese dumpling), yin (meaning feminie), yang (meaning masculine) and fengshui (meaning a geomantic omen) are becoming part of English. Even jia you which is used in cheering the athletes and others to do better, has won great popularity since Beijing's Olympic Games. These are some of the examples to show that "Chinese English" does not hinder the cross-cultural communication. Rather, it helps to make up for what is missed in Chinese-English communication and functions well in the introduction of Chinese culture and its carrier-language into English.

\section{B. The Implication of "Chinese English" in C-E Interpretation}

While "Chinese English" has an important role to play in cross-cultural communication, it is sure not to be neglected in C-E (Chinese-English) interpretation. Since the purpose of interpretation is to reach understanding between parties of different languages, its role is never restricted to "trying to find the closest linguistic equivalent in the target language without being aware of or taking into account the role of the translation operations" (Gile, 1995: 23). In the process of Chinese English communication, reaching cultural understanding can be more important than finding the linguistic equivalents in English language. Therefore, in the case of interpreting expressions with particular Chinese features, the language mediators not only need to find the closest linguistic equivalent, but are supposed to exploit ways of interpreting which might help push these expressions to be accepted by English speakers. Even if the translation is "Chinese English", it still should be encouraged rather than dismissed as poor English.

We would therefore propose to take a positive attitude to "Chinese English" in the process of interpretation since it helps to introduce Chinese characteristics into English and fulfill the purpose of cross-cultural communication. Since most of "Chinese English" is resulted from the translation of words and expressions with Chinese characteristics, in the specific interpretation situation, it is more a matter of how to put them into English. Thus, it is necessary to approach these Chinese expressions according to specific context. The following are some of the suggestive translating methods for the words and expressions with Chinese characteristics in C-E interpretation.

1. Finding the equivalents in English

Interpretation, like translation, is in essence a reproduction of the original work. Therefore, the first principle of interpretation is to be faithful to the original message. When doing C-E interpretation concerning the expressions with Chinese characteristics, a language mediator is supposed to find the most appropriate English equivalents firstly. The version rendered in this way can be most natural to an English ear. The translation of Chinese expression “下岗”(xia gang) might be a good example. It is an expression created in early 1990s when the government carried out the policy of cutting staff for state-own enterprises and factories for the purpose of work efficiency. There appeared a couple of English translations for “下岗” in the past few years. Some of the most popular ones are "get unemployed", "lose job" and "be laid off". According to Webster's Ninth New Collegiate Dictionary, "lay off" means "to cease to employ (a worker) usu. temporarily." This definition best suits the Chinese expression “下岗” because this group of people cut from their present position can get reemployed in other private or state-run enterprises after they are trained and have some skills. Both the Chinese “下岗” and the English "be laid off” imply temporary unemployment. Therefore, among 
the above translations, "be laid off" is more popular and closest in meaning than the others. Thus, it has becomes a popular translation and is used in all the $\mathrm{C}$-E interpretational and translational situations.

2. Transliteration

A popular way of translating Chinese-specific expressions is transliteration, the most direct translation method. The expressions such as typhoon (transliteration of “台风”, meaning tropical cyclone ), gong fu (transliteration of “功夫”, meaning Chinese martial arts) and koutou (transliteration of “磕头”, meaning kneeling down to sb.) all belong to this classification.

Transliteration usually happens when the original finds no equivalence in the target language. Such expressions are rather limited and it takes long for them to be accepted. A very recent example is jia you (transliteration of “加油”, an expression used to cheer athletes to do well in sports games) during the Beijing Olympic Games in which all the viewers in the filed and in front of TV hear it again and again and understand it to be Chinese way of cheering the athletes to do better. Since jia you implies not only encouragement and cheering, but a strong will to do things better or to succeed, its translation should go beyond "China" and "Do better" enthusiastically proposed by some people. The Beijing Games convinced people that the best translation for this word is its transliteration "jia you".

Despite the limited number of the transliterated "Chinese English", they are making their way into English language through repeated use with the deepening of cross-cultural communication. Once accepted, they are likely to become favorite expressions by the English-speaking people when talking about things concerning China.

3. Translation using a transliteration plus explanation

Transliteration is the simplest and most straightforward way of putting Chinese into "Chinese English". However, most "Chinese English" translated in this way make no sense to native speakers of English. To reach understanding and gain acceptance by the English speakers, it is sometimes necessary to resort to explanation after the transliteration. Take “翰林院” (han lin yuan) for example. It is the government office in imperial China in charge of history, literature, chronometer, and government consultation. Although it is quite typical of China and cannot find the equivalence in English, it is so rare that the bare transliteration might be hard to understand. Therefore, it is advisable to plus an explanation in C-E interpretation. This can be very effective in the case of interpretation since the language mediator has much flexibility to arrange the sentences. The way of linking the transliteration and its explanation can be varied according to different situation or the frequency he uses this way of interpreting. He can put in into "han lin yuan, which means imperial academy" or "han lin yuan, meaning imperial academy" or whatever way he thinks might be appropriate to reach understanding.

4. Literal translation

Literal translation, as "the basic translation procedure" (Newmark 2001:70), has the advantage of keeping the original flavor and cultural tint. It is effective in communicating the source culture since it usually follows the original closely, thus keeping the vividness of the expressions. It's fairly easy today to see that the most frequently used “Chinese English” is the literal translation of the particular Chinese expressions. Cultural Revolution (文化大革命), Great Leap Forward (大跃进), One Country, Two Systems (一国两制), A Harmonious Society (和谐社会) and paper tiger (纸老虎) are just a few examples.

"Chinese English" translated in a literal way might not sound natural to a stranger of Chinese context and are sometimes considered too literal to be good English. But, considering the role of translation which is not as simple as putting message across to reach understanding and achieve communication between speakers of different languages, it might be tolerated culturally. A translator is not only a language mediator, but also a "cultural mediator" (Katan 2004:15). Therefore, he also has the responsibility of introducing Chinese culture to the outside world besides language transmission. Communication is never one-sided. While people in China are deeply influenced by the English culture through the media of language translation, it is also necessary to introduce Chinese culture into English speaking countries. "Chinese English", if used frequently enough, will function well in introducing Chinese culture into English. Understanding language is a short-term activity, but understanding and accepting a culture is a long term goal of cross cultural communication. So why don’t C-E translators put “佛祖保佑”(fo zu bao you) into “Buddha bless me” instead of "God bless me" since Chinese believe more in Buddha than in God.

\section{CONCLUSION}

"Chinese English", a direct result of communication between Chinese and the English speaking nations, may not easily acceptable by the English. However, the significance of the role it plays in introducing China to the outside world is undeniable. Therefore, as language mediators and culture transmitters, C-E interpreters are supposed to take an earnest attitude toward it rather than obviate it as hampering cross-cultural communication. As for the approaches taken to interpret the Chinese specific expressions into English, their acceptability in the target language should be considered fully so as not to cause misunderstanding, but to reach effective communication.

\section{REFERENCES}

[1] Ge, Chuangui. (1984). Some Problems on Translation. Translation Communication. Editorial Office. Beijing. Foreign 
Language Teaching and Research Press. 1984. 357-372. [originally in Translation Communication 1980:2]

[2] Gile, Daniel. (1995). Basic Concepts and Models for Interpreters and Translator Training. Philadelphia: John Benjamins Publishing Co.

[3] Huang, Jinqi. (1998). Chinese Trend of Western Translation should be Affirmed. Chinese Translators Journal.1998:1

[4] Jia, Guanjie, Xiang, mingyou. (1997). An Argument for Chinese English. Foreign Language and Their Teaching. 1997:5. 11-12

[5] Katan, David (1999). Translating Cultures: An Introduction for Translators, Interpreters and Mediators. Manchester: St.Jerome Publishing.

[6] Li, Shaohua. (2006). Chinese English in English Globalization and Localization Perspectives. Yinshuan: Ning Xia People's Press

[7] Li, Wenzhong. (1993). Chinese English and Chinglish. Foreign Language Teaching and Research. 1993:4. 18-24

[8] Li, xingqiao. (2008). The Defining of Chinese English. Journal of Hubei University of Economics (Humanities and Social Sciences). 2008:2.149-150

[9] Liao, Huaying. (2007). A Glimpse of Chinese Culture. Foreign Language Teaching and Research Press.

[10] Luo, Yunzhi. (1998). The Prospect of Chinese English. Foreign Language and Their Teaching 1998:5.24-25

[11] Newmark, Peter. (2001). A Textbook of Translation. Beijing: Foreign Language Teaching and Research Press.

[12] Nida, Eugene A and C. R. Taber. (1969). The Theory and Practice of Translation. Leiden: Braill

[13] Qiao, Xing. (2008). The Function of Chinese English in Cross-Cultural Communication. Journal of Xinyang Normal University. (Philos. \&Soc. Sci. Edit.) 2008:4.99-102

[14] Shi, Yu. (2008). On 'Chinese English' from the Cultural Difference of China and the West. Journal of Xian Ning University. 2008:10.50-51

[15] Xie, Zhijun. (1995). Chinese English-Interfering Variation in Cross-Cultural Communication. Modern English. 1995:3.7-10

[16] Wang, Rongpei. (1991). The Objective Existence of Chinese English. Journal of PLA University of Foreign Languages. 1991:1.1-8

[17] Webster's Ninth New Collegiate Dictionary. (1988). Beijing: World Publishing Corporation.

[18] Yu, Tongmeng. (2007). Chinese Festivals. Beijing: Chinese Textile Press.

[19] Zhu, Ninghong. (2005). An Overview of Chinese Folk Tradition and Custom-Festivals and Entertainment. Beijing: Chinese Materials Press.

[20] Zhao, Ruimin. (1988). Names and Chinese Culture. Beijing: Chinese People's University Press.

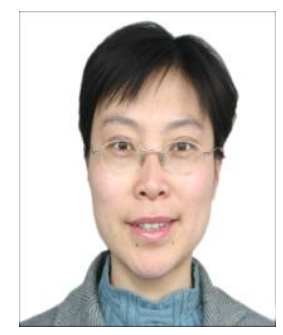

Yi Chen was born in Shaanxi, China in 1973. She received her master's degree in English language and culture from Xian Foreign Languages University, China in 1998.

She is currently an associate professor in the School of Humanities, Beijing University of Posts and Telecommunications, Beijing, China. Her research interests include translation and language teaching. 